\title{
Evaluation of electrical equipment service life on the basis of its status index trend
}

\author{
Alexander Nazarychev ${ }^{1 *}$, Alexey Tadzhibaev ${ }^{1}$, Dmitry Andreyev ${ }^{2}$ \\ ${ }^{1}$ PPEIPD, Russia \\ ${ }^{2}$ JSC «Zarubezhenergoproyekt», Russia
}

\begin{abstract}
This paper presents an approach designed to evaluate electrical equipment service life indicators, taking into account the changes of its technical status integral characteristic, i.e., of status index. This approach combines some previously developed methods of evaluating EE technical service life and its status index, and it allows to carry out a quantitative evaluation of electrical equipment service life depending on the actual accrued operating time of equipment, considering actual operating conditions and modes. This report also presents an example of application of this approach to evaluate the reliability of different types of equipment.
\end{abstract}

\section{Introduction}

In the capacity of the main index of electrical equipment (EE) service life Paper [1] proposes to use technical service life, which can most completely reflect the property of reliability.

EE service life is the total accrued operating time of EE following its operation start or its latest major repairs, till it reaches a limit state. Accrued operating time (a calendar-based operating time) can be determined by either the time length or the volume of energy facility operation [1]. A limit state is a condition, when any continued equipment operation must be terminated due to unavoidable violations of safety regulations or because of an unavoidable operation capacity reduction, or any impermissible operation level drop. Accrued operating time can be measured by both continuous units and/or discrete units of measurement. Applying the notion of accrued operating time, we shall undertake to solve the problem of evaluating EE service life, taking into account its technical status variations under different operating conditions.

\section{Evaluation of electrical equipment service life indicators}

Any actual service life of EE depends from its technical status (TS). The evolution of equipment TS variations is determined by influencing factors, operating conditions and modes [1]. In terms of quantity, the effect of EE operating conditions and modes on EE TS, for example, in the group of companies belonging to the PJSC "Rosseti", is determined by the status index (SI) value, which is defined on the basis of textual algorithms (TSI), applying major equipment operation parameters $[1,2,3]$. The most significant operation conditions are stipulated in normative-technical documentation (NTD). Fig.1 displays a diagram showing service life drawdown and the corresponding SI changes when EE is run under normative (standard) conditions (n.c.).

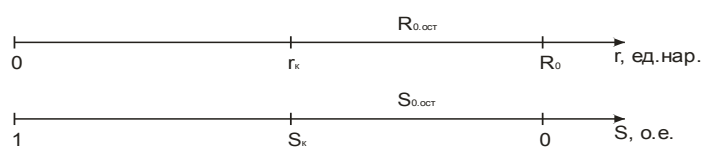

Fig. 1. A diagram showing EE service life drawdown and SI changes during operation under normative conditions. The units of measurement of used service life are given along Axis $r$, accrued operation time units (u.aot).

The $\mathrm{R}_{0}$ moment on Axis $\mathrm{r}$, which shows accrued operation time, corresponds to EE transition to a limit state (EE SI, designated by "S", is equal to 0 ). Then the accrued operation time interval in terms of its volume will be equal to $E E$ normative service life $\mathrm{R}_{0}$, provided that EE was operated on the whole under n.c. stipulated in normative-technical documentation. Let us assume that EE was running under n.c. during an interval starting from 0 (the EE SI "S" is 1) up to a certain checking point $r_{c h}$. (the SI of EE is equal here to an intermediary value $\mathrm{S}_{\mathrm{ch}}$.) and therefore EE has used its service life in the volume of $r_{\text {ch. }}$. In that case the remaining normative service life can be defined as $\mathrm{R}_{0 . \text { rem. }}=\mathrm{R}_{0}-\mathrm{r}_{\text {ch. }}$, on the condition that, following the moment $r_{\text {ch. }}$ on the accrued operation time Axis $r$ (Fig. 1), EE will also be running under n.c. In that case EE will have a spare SI $\mathrm{S}_{0 . \text { rem. }}$ prior to its transition into a limit state, when the SI value is $S=0$.

The wear and tear of EE is determined by its operation modes, by some external operation conditions and by influencing factors. Thus, if operation conditions differ from n.c., the service life value $r_{\text {ch. }}$ has to be

\footnotetext{
Corresponding author: rector@peipk.spb.ru
} 
corrected, taking into consideration EE operation modes and conditions. If it is known that within the accrued service period from $r_{\text {ch. }}$ till $R_{0}$ EE will also be running under conditions which differ from n.c., then the $\mathrm{R}_{0 . \text { rem. }}$ value will have to be corrected, too, taking into account EE actual operating conditions. As a result of these corrections certain values of actually used service life $\mathrm{R}$ and of actually remaining service life $R_{\text {rem. }}$. will be obtained. Figure 2 shows a diagram displaying the used service life and the corresponding status index changes (SI), if EE was run under different conditions which differ from standard ones.

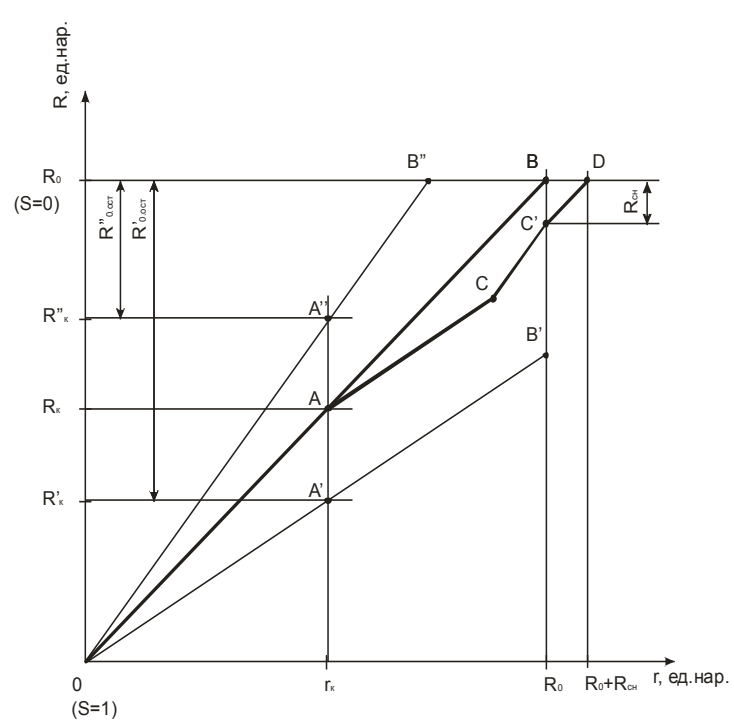

Fig. 2. A diagram showing EE used service life and the corresponding EE SI changes in cases, when equipment is operated under non-normative conditions.

The abscissa and the ordinate axes (ref. Fig. 2) are axes which present the service life drawdown. On the $\mathrm{x}$ axis the accrued operation time of EE is marked in such a way, as if equipment were running under n.c., while along the axis of ordinates a corrected accrued operation time is marked, considering EE actual operation conditions. Therefore, the abscissa axis is an axis which shows a calendar-based operating time, while the axis of ordinates shows an actually accrued operation time. The origin of coordinates corresponds to the beginning of operation of a new piece of equipment, whose SI $\mathrm{S}=1$ r.u.(relative unit). Let us then mark on the $\mathrm{x}$-axis a certain calendar-based accrued operation time $r_{c h}$. This

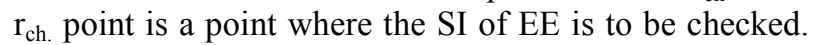
If during the interval of accrued calendar-based operation time between 0 and $r_{c h}$. EE was on the whole running under n.c., then its TS was worsening, as this is stipulated in NTD, and that corresponds to the $0 \mathrm{AB}$ direct line. If equipment running conditions were of a lighter character (direct line $0 \mathrm{~A}^{\prime} \mathrm{B}^{\prime}$ ), then equipment TS was worsening at a slower rate, if compared with its worsening rate under normative conditions (its SI will be higher, than it would be under n.c.). If operating conditions were on the whole of a heavier character (direct line 0A' 'B',), then, conversely, the said TS was worsening faster (the SI will be lower, than it would be under n.c). Consequently, along the y-axis the value of accrued operating time can be marked, which corresponds to the actually consumed service life $\mathrm{R}$ during the accrued operating time $r_{\text {ch. }}$. under certain possible operation conditions. Besides, the $\mathrm{R} \leq \mathrm{R}_{0}$ relationship will always be true. Point $A$, with its coordinates being $\left(\mathrm{r}_{\mathrm{ch}} ., \mathrm{R}_{\mathrm{ch}}\right.$.), characterizes the accrued operation time $r_{c h}$. of EE in such a way, as if EE were running under n.c., and the corresponding actually used service life $R_{c h}$. In this instance the equality $R_{c h}=r_{c h}$ will be true. Point $\mathrm{B}$ corresponds to the beginning of EE limit state (the SI of TS is $S=0$ ), provided that within the accrued operation time length $r=R_{0}$ EE was running under normative operation conditions only. Point A', with its coordinates being $\left(r_{c h}, R^{\prime}{ }_{c h}\right.$,), characterizes the accrued operation time $r_{c h}$ of EE in such a way, as if it were on the whole running under lighter conditions. In this case, the following relation $\mathrm{R}_{\mathrm{ch}}{ }_{\mathrm{ch}}<\mathrm{r}_{\mathrm{ch}}<\mathrm{R}_{\mathrm{ch}}$ will be true. However, point ' $\mathrm{B}$ ' does not correspond to the onset of any EE limiting state, because the actually used service life $R_{\text {' }}$ has not reached yet the value $R_{0}$. Then, following the expiry of the accrued operation time $r=R_{0}$, the service life of EE can be extended and its above-standard operation can be maintained till the moment, when SI becomes equal to $\mathrm{S}=0$. Point $\mathrm{A}$ ", with its coordinates being $\left(\mathrm{r}_{\mathrm{ch}}, \mathrm{R}{ }^{\prime}{ }_{\mathrm{ch}}\right.$,), characterizes the accrued operation time $r_{\text {ch }}$ of EE in such a way, as if it were running under heavier conditions only, and also its corresponding actually used service life R'" case the following relation $\mathrm{R}^{\prime}{ }_{\mathrm{ch}}>\mathrm{r}_{\mathrm{ch}}>\mathrm{R}_{\mathrm{ch}}$ will be true. Besides, Point B" corresponds to the onset of EE limit state (SI TS $S=0$ ), however, the actually spent service life $\mathrm{R}_{\text {ch }}$ had reached the $\mathrm{R}_{0}$ value faster, than that would have been under n.c.. Therefore, EE has to be decommissioned at an earlier time, than that would take place under n.c., i.e., when $\mathrm{SI}$ is $\mathrm{S}=0$, but that will happen before $r$ reaches the $R_{0}$ value. If subsequently, after Point A, EE is going to be operated under normative conditions and operation modes, then its accrued operating time will afterwards correspond to normative values. In that case the remaining normative service life for Point $A$ will be defined as follows: $\mathrm{R}_{0 \text {.rem. }}=\mathrm{R}_{0}-\mathrm{R}_{\text {ch }}$, while for Points $\mathrm{A}^{\prime}$ and $\mathrm{A}^{\prime}$ ' it will be, accordingly, expressed as: $\mathrm{R}_{0 . \mathrm{rem}}^{\prime}=\mathrm{R}_{0}-\mathrm{R}_{\text {ch }}^{\prime}$ and $\mathrm{R}^{\prime}{ }_{0 . \mathrm{rem}}=\mathrm{R}_{0}-\mathrm{R}$ ' ${ }_{\mathrm{ch}}$. If though the conditions of further operation are going to differ from standard values, then the value $\mathrm{R}_{0 . \text { rem. }}$ must be corrected, too, considering probable operation conditions, in order to determine the value of the actually remaining service life $R_{\text {rem}}$. When the actual accrued operating time reaches the value of the normative service life $\mathrm{R}_{0}$, EE will pass on to its limit state and it has to be decommissioned.

Let us now examine the $0 A C C$ 'D broken line which characterizes the EE operation under different operating conditions. Prior to Point A, as it has already been mentioned above, EE had been running under n.c. From Point A till Point $\mathrm{C}$ equipment operation on the whole was under lighter conditions, while from Point $\mathrm{C}$ till point C' it was on the whole being carried out under heavier conditions. At the moment of time when accrued operating time $r$ reached a normative service life value, EE had not really used it up completely, i.e., the actually 
used service life proved to be shorter, than the normative one. Therefore, EE operation can be kept on. In this case the remaining normative service life will be equal to EE service life in the conditions of above-standard operation $\mathrm{R}_{\mathrm{as}}$. If the said above-standard operation is going to be carried out under conditions, which differ from normative ones, then $\mathrm{R}_{\text {as. }}$ should be corrected, taking into considering any planned out operation conditions.

For the sake of convenience, while making calculations and in order to compare the results of calculations concerning different EE types and voltage classes, and also so as to be able to consider the effect of operation conditions on the process of EE service life drawing down, it is expedient to pass on to relative units for measuring accrued operation time. In such a case the normative service life $\mathrm{R}_{0}$ should be taken from NTD as the basic service life value for normative conditions. By relating all the other values of accrued operating time and service life values to $R_{0}$ it is then possible to obtain relative units for measuring EE accrued operating time.

The SI indicator "S" allows to make a quantitative evaluation of equipment TS and it is determined by means of calculations, considering the expert values of weight factors [3]. Besides, the SI value will be changing, depending upon the calendar-based accrued operating time, this why in a common case the said SI is a function of accrued operating time. The EE status will become a limiting one, when its $\mathrm{SI} S=0$, which also corresponds to the moment, when EE service life had been completely drawn down. The status of EE, when the SI value is $S=1$, corresponds to the TS of a new piece of EE, whose operation has not yet started, while its actually spent service life is $R=0$.

Evidently, the operating life of EE and, consequently, its technical service life, will proportionally depend upon the dynamic character of EE TS variations. That is to say, any changes of the actual EE technical service life over a certain calendar interval of accrued operating time are determined by the changes of EE SI.

In a common case, the value of SI can be presented in the form of the following function:

$$
\mathrm{S}=\mathrm{f}\left(\mathrm{r},\left\{\mathrm{X}_{\mathrm{i}}(\mathrm{r})\right\}\right)
$$

where $\mathrm{r}-$ is accrued operating time, $\left\{\mathrm{X}_{\mathrm{i}}(\mathrm{r})\right\}-$ is a multitude of parameters upon which SI depends.

Let us now examine an infinitely small interval of the $\mathrm{dr}$ calendar-based operating time, and to which the actually drawn down service life $\mathrm{dR}$ corresponds. If during its accrued operating time dr EE was running under n.c., then $\mathrm{dR}=\mathrm{dr}$. If, however, its working conditions differed from its normative conditions, then, taking into account the fact that dr tends towards zero, it is reasonable to assume that the relationship between the actually spent service life will be proportional to the relationship of EE SI over the dr interval. The SI function $\mathrm{S}$ is monotonically diminishing within the interval of time between repairs, and, accordingly, the relationship of EE SI variations during an infinitely small interval $\mathrm{dr}$ in case of normative and non-normative operation will tend towards the relationship of the SI value at the beginning of the dr operating time interval.
Furthermore, during the said infinitely small interval of accrued operating time dr any $\left\{\mathrm{X}_{\mathrm{i}}\right\}$ parameter changes can be neglected. Then it is logically correct to write down the following expression:

$$
\begin{gathered}
\frac{\mathrm{dR}}{\mathrm{dr}}=\frac{1-\mathrm{S}(\mathrm{r})}{1-\mathrm{S}_{0}(\mathrm{r})} \\
\mathrm{dR}=\mathrm{dr} \frac{1-\mathrm{S}(\mathrm{r})}{1-\mathrm{S}_{0}(\mathrm{r})},
\end{gathered}
$$

where $\mathrm{S}_{0}(\mathrm{r})$ - is the function of EE SI variations under normative conditions; $\mathrm{S}(\mathrm{r})$ - is the function of EE SI changes under actual operation conditions.

Expression (3) is a differential equation of the first order. Let us integrate both its parts over the interval of accrued calendar-based operating time from $\mathrm{r}_{1}$ till $\mathrm{r}_{2}$ :

$$
\mathrm{R}_{12}=\int_{\mathrm{r}_{1}}^{\mathrm{r}_{2}} \frac{1-\mathrm{S}(\mathrm{r})}{1-\mathrm{S}_{0}(\mathrm{r})} \mathrm{dr},
$$

where $R_{12}$ - is the actually drawn out service life over the interval of accrued operating time $\left[r_{1} ; r_{2}\right]$, depending on the value of SI S(r).

Expression (4) is most commonly used to determine the actually consumed service life of EE over a prescribed accrued operation time interval, considering the EE TS evaluation made on the basis of the TS value. The formula used to calculate a specific accrued operating time can change depending on the way Function S(r)-SI is presented, and depending on the accrued operating time $r$.

For the moment of time, when EE operation is started, $r=r_{1}=0$. Let us assume that $r=r_{2}=r_{c h . i}$ is a certain point of checking, for which it is necessary to determine the actually drawn down service life $R_{c h . i}$. If Functions $\mathrm{S}(\mathrm{r}), \mathrm{S}_{0}(\mathrm{r})$ are known for the whole interval of calendar-based operating time $r \in\left[0 ; r_{c h . i}\right]$, i.e., it is known in what way EE TS was changing, then Expression (4) will acquire the following form:

$$
\mathrm{R}_{\mathrm{K} . \mathrm{i}}=\int_{0}^{\mathrm{r}_{\mathrm{K} . \mathrm{i}}} \frac{1-\mathrm{S}(\mathrm{r})}{1-\mathrm{S}_{0}(\mathrm{r})} \mathrm{dr},
$$

where $R_{\text {ch.i }}$ - is the actually drawn down service life of EE during its operating time from the beginning of equipment operation in the scope of $r_{\text {ch }}$.

If we assume that $r_{c h . i}=R_{0}$, then Expression (5) will acquire the following form:

$$
\mathrm{R}=\int_{0}^{\mathrm{R}_{0}} \frac{1-\mathrm{S}(\mathrm{r})}{1-\mathrm{S}_{0}(\mathrm{r})} \mathrm{dr},
$$

where $\mathrm{R}$ - is the actually drawn down service life of EE during its operating time in a scope, which corresponds to its normative service life $\mathrm{R}_{0}$.

The actually used service life of EE $R_{\text {ch.i }}$ at the moment of checking $r_{\text {ch.i }}$ must always be compared with the value $\mathrm{R}_{0}$. If $\mathrm{R}_{\text {ch. }} \approx \mathrm{R}_{0}$, then the operation of $E E$ has to 
be terminated. If $\mathrm{R}_{\text {ch.i }}<\mathrm{R}_{0}$, then $\mathrm{EE}$ operation can be continued. In this case the remaining service life of $\mathrm{EE}$ is to be determined and it must be determined, how long more it can still keep running. The value of the actually spent service life $R_{c h . i}$ at the moment of checking must not exceed the $\mathrm{R}_{0}$ value. If during $\mathrm{K}$-intervals the intensity of factors affecting $\mathrm{EE}$ is going to differ from normative values, then the actual summed up service life of EE, which has been used during these intervals of EE operating time $\Delta \mathrm{r}_{\Sigma}$, can be calculated by the following expression:

$$
\Delta \mathrm{R}_{\Sigma}=\sum_{\mathrm{j}=1}^{\mathrm{K}} \int_{0}^{\mathrm{r}_{\mathrm{j}}} \frac{1-\mathrm{S}(\mathrm{r})}{1-\mathrm{S}_{0}(\mathrm{r})} \mathrm{dr}
$$

where $\mathrm{j}=1 \ldots \mathrm{K}-$ is the number of intervals, during which some abnormal operating conditions can be observed; $r_{j}-$ is a calendar-based accrued operating time during the $\mathrm{j}$-th interval. And then: $\sum_{\mathrm{j}=1}^{\mathrm{K}} \mathrm{r}_{\mathrm{j}} \leq \mathrm{R}_{0}$.

Expression (7) is true in case the spent service life period of EE and, consequently, any changes of its TS do not depend on EE accrued operating time before the $r_{j}$. interval, which is being examined.

Thus, any service life value possess an additivity property [1], whose essence lies in the fact the total actually spent service life $\Delta R_{\Sigma}$ consists of the summed up values of EE actually used service life at any single $j$-th section of accrued operating time $r_{j}$. The actually spent service life $R_{c h . i}$ during the accrued operating time in the scope of $r_{c h . i}$ will be determined as the sum of EE accrued operating time under normative $\Delta \mathrm{r}_{0}$ and under non-normative operation conditions $\Delta \mathrm{r}_{\Sigma}$ :

$$
\mathrm{R}_{\mathrm{\kappa .i}}=\Delta \mathrm{r}_{0}+\Delta \mathrm{r}_{\Sigma}
$$

The values of $\Delta R_{0}$ are determined by the following expression:

$$
\Delta \mathrm{r}_{0}=\mathrm{r}_{\mathrm{k} . \mathrm{i}}-\sum_{\mathrm{i}=1}^{\mathrm{K}} \mathrm{r}_{\mathrm{j}}
$$

By introducing Expressions (7) and (8) into (9) a formula can be obtained to determine the actually spent service life of EE $\mathrm{R}_{\mathrm{ch.i}}$ during a calendar-based operating time in the scope of $r_{\text {ch.i. }}$ :

$$
\mathrm{R}_{\mathrm{K} . \mathrm{i}}=\mathrm{r}_{\mathrm{k} . \mathrm{i}}-\sum_{\mathrm{i}=1}^{\mathrm{K}} \mathrm{r}_{\mathrm{j}}+\sum_{\mathrm{j}=1}^{\mathrm{K}} \int_{0}^{\mathrm{r}_{\mathrm{j}}} \frac{1-\mathrm{S}(\mathrm{r})}{1-\mathrm{S}_{0}(\mathrm{r})} \mathrm{dr} .
$$

Let us transform Formula (10) and we shall get then:

$$
\mathrm{R}_{\mathrm{K} . \mathrm{i}}=\mathrm{r}_{\mathrm{k} . \mathrm{i}}+\sum_{\mathrm{j}=1}^{\mathrm{K}}\left(\int_{0}^{\mathrm{r}_{\mathrm{j}}} \frac{1-\mathrm{S}(\mathrm{r})}{1-\mathrm{S}_{0}(\mathrm{r})} \mathrm{dr}-\mathrm{r}_{\mathrm{j}}\right)
$$

If $r_{\text {ch.i }}=R_{0}$, then the actually spent service life of EE $\mathrm{R}$ during the calendar-based operating time of $\mathrm{EE}$ in the volume of normative service life can be determined as follows:

$$
\mathrm{R}=\mathrm{R}_{0}+\sum_{\mathrm{j}=1}^{\mathrm{K}}\left(\int_{0}^{\mathrm{r}_{\mathrm{j}}} \frac{1-\mathrm{S}(\mathrm{r})}{1-\mathrm{S}_{0}(\mathrm{r})} \mathrm{dr}-\mathrm{r}_{\mathrm{j}}\right)
$$

Formulae (6) and (12) allow us to determine any actually spent service life during the period of normative EE operation (during the accrued operating time in the scope of $\mathrm{R}_{0}$ ), while Formulae (5) and (10) allow to determine any actually spent service life during the calendar-based accrued operating time $r_{c h . i}$ till the $i$-th moment of checking. If EE had already drawn down a certain service life span $R_{\text {ch.i }}$ by the moment of checking $r_{c h . i}$, then we can determine the value of its remaining normative service life $\mathrm{R}_{0 \text {.rem, }}$, if any subsequent operation of $\mathrm{EE}$ is going to take place under n.c., on the basis of the following expression:

$$
\mathrm{R}_{0 . \text { ост }}=\mathrm{R}_{0}-\mathrm{R}_{\text {к.i }}=\mathrm{R}_{0}-\mathrm{r}_{\text {к.i }}+\int_{0}^{\mathrm{r}_{\text {к.j }}} \frac{1-\mathrm{S}(\mathrm{r})}{1-\mathrm{S}_{0}(\mathrm{r})} \mathrm{dr}
$$

or (for the K-intervals of non-normative operation till the point of checking):

$$
\mathrm{R}_{0 . \text { oc }}=\mathrm{R}_{0}-\mathrm{R}_{\mathrm{K} . \mathrm{i}}=\mathrm{R}_{0}-\mathrm{r}_{\mathrm{K} . \mathrm{i}}+\sum_{\mathrm{j}=1}^{\mathrm{K}}\left(\mathrm{r}_{\mathrm{j}}-\int_{0}^{\mathrm{r}_{\mathrm{j}}} \frac{1-\mathrm{S}(\mathrm{r})}{1-\mathrm{S}_{0}(\mathrm{r})} \mathrm{dr}\right)
$$

If $r_{c h . i}=R_{0}$, i.e., checking is undertaken, when the calendar-based accrued operating time $r$ is equal to the normative service life $\mathrm{R}_{0}$. In this case Expressions (13) and (14) will, accordingly, acquire the following form:

$$
\begin{gathered}
\mathrm{R}_{0 . \text { ост }}=\int_{0}^{\mathrm{R}_{0}} \frac{1-\mathrm{S}(\mathrm{r})}{1-\mathrm{S}_{0}(\mathrm{r})} \mathrm{dr} \\
\mathrm{R}_{\text {0.ост }}=\sum_{\mathrm{j}=1}^{\mathrm{K}}\left(\mathrm{r}_{\mathrm{j}}-\int_{0}^{\mathrm{r}_{\mathrm{j}}} \frac{1-\mathrm{S}(\mathrm{r})}{1-\mathrm{S}_{0}(\mathrm{r})} \mathrm{dr}\right)
\end{gathered}
$$

Under certain known, non-standard conditions of further $\mathrm{EE}$ operation the value of $\mathrm{R}_{0 \text {.rem. }}$ has to be corrected, considering the forecast TS value of $\mathrm{EE}$ according to Expression (4), by adopting $r_{1}=R_{\text {ch.i }}$ (the current point of checking), and $\mathrm{r}_{2}=\mathrm{R}_{0}$ :

$$
\mathrm{R}_{\mathrm{ocT}}=\int_{\mathrm{R}_{\mathrm{K} . \mathrm{i}}}^{\mathrm{R}_{0}} \frac{1-\mathrm{S}(\mathrm{r})}{1-\mathrm{S}_{0}(\mathrm{r})} \mathrm{dr}
$$

If necessary, it is also possible to apply Expression (11) by introducing $r_{c h . i}=R_{0 . r e m}$. 


$$
\mathrm{R}_{\text {ocT }}=\mathrm{R}_{0 . \text { ocT }}+\sum_{\mathrm{j}=1}^{\mathrm{K}}\left(\int_{0}^{\mathrm{r}_{\mathrm{j}}} \frac{1-\mathrm{S}(\mathrm{r})}{1-\mathrm{S}_{0}(\mathrm{r})} \mathrm{dr}-\mathrm{r}_{\mathrm{j}}\right) .
$$

After making this calculation, it is necessary to evaluate the difference between $R_{\text {rem }}$. and $R_{0 \text {. rem }}$ so as to be convinced that $R_{\text {rem }} \leq R_{0 . r e m}$. In the opposite case, $E E$ operation, with due account taken of its TS forecast value, should not be continued during the entire interval of the remaining accrued calendar-based operating time $r=R_{0 . r e m}$. EE must then be operated either under lighter operation conditions, which will allow to reduce the tempo of its TS worsening and thus to extend the EE service life, or the period of equipment operation will have to be reduced by the value of $\left(\mathrm{R}_{\mathrm{rem}}-\mathrm{R}_{0 . \mathrm{rem}}\right)$. Since it is rather a complicated matter to forecast the operation conditions and modes of EE for any future periods, it is assumed that EE, after the point of checking, will be running in the same mode, as its mode had been before the said checking point, and in that case its TS and SI will be changing in a similar way.

For the sake of convenience, expressions used to determine the actually spent service life of EE can be described by means of relative units (r.u.), to measure EE accrued operating time; for example, Expression (3) will then have the following form:

$$
\mathrm{R}_{12}^{*}=\int_{\mathrm{r}_{1}}^{\mathrm{r}_{2}^{*}} \frac{1-\mathrm{S}(\mathrm{r})}{1-\mathrm{S}_{0}(\mathrm{r})} \mathrm{dr}^{*},
$$

where $R_{12}^{*}=R_{12} / R_{0}$ - is the relative, actually used service life of EE during its accrued operating time $\left[\mathrm{r}_{1}^{*} ; \mathrm{r}_{2}^{*}\right]$, depending upon its SI $\mathrm{S}\left(\mathrm{r}^{*}\right) ; \mathrm{r}_{1}^{*}=\mathrm{r}_{1} / \mathrm{R}_{0}$; $\mathrm{r}_{2}=\mathrm{r}_{2} / \mathrm{R}_{0}$.

Let us examine the possibility to determine EE service life, if all the initial data are available. The graphs shown in Figures 3 and 4 are not linked to any specific EE type, they just display the potential of the currently developed approach.

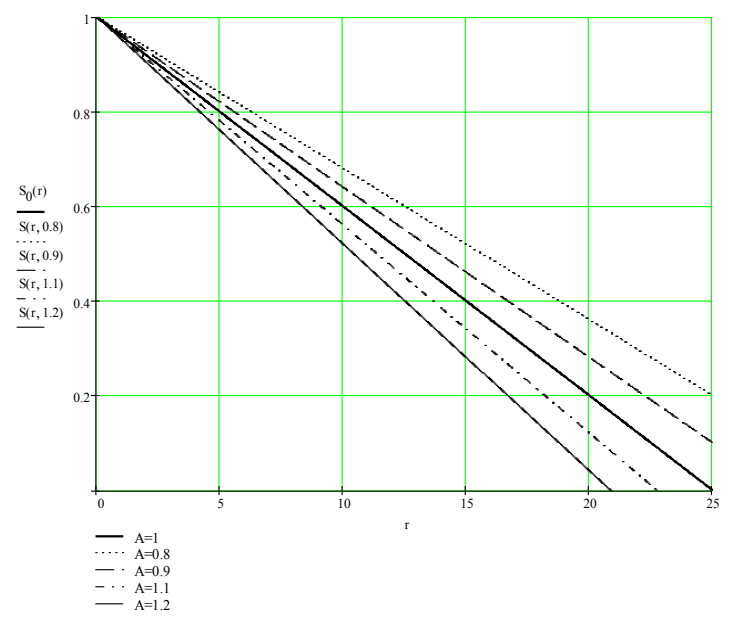

Fig. 3. Dependences of the values of SI S(r) of EE from its accrued calendar-based operating time r, for different Factor A values The value of $\mathrm{A}=1$ corresponds to $\mathrm{EE}$ normative operation conditions.
By applying a linear sort of approximation for EE SI $[1,2]$ the value of actually used service life, taking into account any changes of SI S(r), will be determined in the following way:

$$
\mathrm{R}_{\mathrm{K}}=\int_{0}^{\mathrm{r}_{\mathrm{K}}} \frac{1-\mathrm{S}(\mathrm{r})}{1-\mathrm{S}_{0}(\mathrm{r})} \mathrm{dr}=\int_{0}^{\mathrm{r}_{\mathrm{K}}} \frac{\mathrm{m}}{\mathrm{m}_{0}} \mathrm{dr}=\mathrm{Ar}_{\mathrm{K}},
$$

where $r_{\text {ch. }}-$ is the accrued calendar-based operating time of $\mathrm{EE}$ at the point of checking; $\mathrm{R}_{\mathrm{ch} .}$ - and it is the actually consumed service life period at the point of checking.

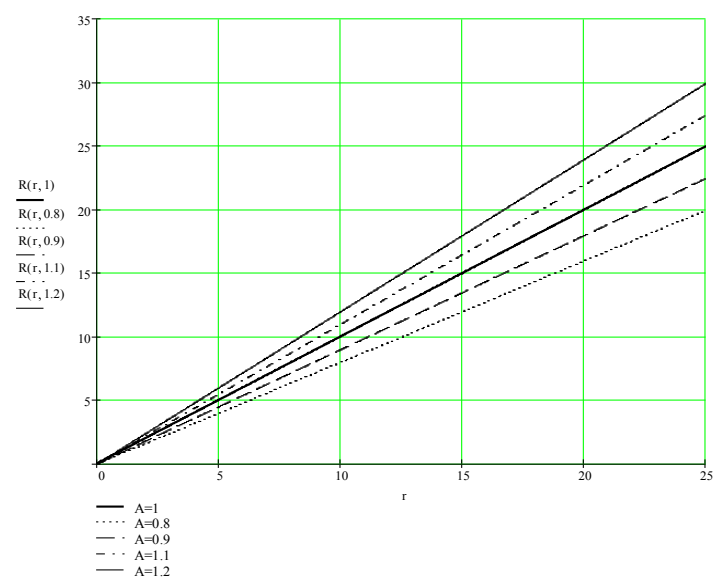

Fig. 4. Dependences of the actually spent service life R of EE from its accrued calendar-based operating time, for different values of Factor $\mathrm{A}$. The value of $\mathrm{A}=1$ corresponds to n.c.

In Formula (20) Factor A expresses the relation of EE SI, when EE is operating under certain actual conditions, to the value of EE SI, under n.c., with the accrued operating time here having the volume $r_{\text {ch }}$. If $\mathrm{A}>1$, then the TS of EE will be worsening faster (under heavier conditions), if $\mathrm{A}<1$, then EE TS will be worsening at a slower rate (under lighter conditions). If $\mathrm{A}=1$, then $\mathrm{EE}$ is running under n.c.

Figure 3 presents the dependences of EE SI variations from the accrued calendar-based operating time $\mathrm{r}$ for different $\mathrm{A}$ values. Fig. 4 shows the dependences of the actually used service life $\mathrm{R}$ from the accrued calendar-based operating time $r$ for different values of $A$. These dependences are formed on the basis of Expression (20). The A factor for certain concrete EE can be formed on the basis of its operation process data. The examples of initial data, received from one of the Inter-Regional Network Companies in order to obtain Factor A, are presented in Table 1. 
Table 1. Approximation Factor Values of the Function of SI Variations.

\begin{tabular}{|c|c|c|c|}
\hline EE Type & EE Model & $\mathbf{m}$ & $\mathbf{m}_{0}$ \\
\hline Transformer & $\begin{array}{l}\text { TMH(TMN)- } \\
6300 / 110 / 10\end{array}$ & -0.02670 & -0.04 \\
\hline $\begin{array}{l}\text { Station } \\
\text { transformer }\end{array}$ & $\begin{array}{l}\text { ТМГСУ(TMGS } \\
\text { U)11-160/10 }\end{array}$ & -0.02280 & -0.04 \\
\hline $\begin{array}{l}\text { Circuit breaker } \\
10 \mathrm{kV}\end{array}$ & $\begin{array}{l}\text { ВМП(VMP)- } \\
10 \Pi(P)-630-20\end{array}$ & -0.01850 & -0.04 \\
\hline $\begin{array}{l}\text { Circuit breaker } \\
10 \mathrm{kV}\end{array}$ & VD-4(VD-4) & -0.14570 & -0.04 \\
\hline $\begin{array}{l}\text { Circuit breaker } \\
110 \mathrm{kV}\end{array}$ & $\begin{array}{l}\text { BMT-110Б- } \\
\text { 25/1250 (VMT- } \\
\text { 110B-25/1250) }\end{array}$ & -0.02230 & -0.04 \\
\hline $\begin{array}{l}\text { Circuit breaker } \\
110 \mathrm{kV}\end{array}$ & $\begin{array}{l}\text { ВМТ-110Б- } \\
\text { 25/1250УХЛ1 } \\
\text { (VMТ-110В- } \\
\text { 25/125UKhL1) }\end{array}$ & -0.01170 & -0.0357 \\
\hline $\begin{array}{l}\text { Tripper } \\
10 \mathrm{kV}\end{array}$ & $\begin{array}{l}\text { PB3-10/400 I } \\
\text { (RVZ-10/400 I) }\end{array}$ & -0.01350 & -0.0333 \\
\hline $\begin{array}{l}\text { Tripper } \\
10 \mathrm{kV}\end{array}$ & $\begin{array}{l}\text { РЛНД-10/630 } \\
\text { (RLND-10/630) }\end{array}$ & -0.01010 & -0.04 \\
\hline $\begin{array}{l}\text { Tripper } \\
35 \mathrm{kV}\end{array}$ & $\begin{array}{l}\text { PHTA-35/125 } \\
\text { (RNTA-35/125) }\end{array}$ & -0.0081 & -0.04 \\
\hline $\begin{array}{l}\text { Current } \\
\text { transformer }\end{array}$ & $\begin{array}{l}\text { ТФНД-110M-II } \\
\text { (TFND-110M- } \\
\text { II) }\end{array}$ & -0.02300 & -0.0333 \\
\hline $\begin{array}{l}\text { Voltage } \\
\text { transformer }\end{array}$ & $\begin{array}{l}\text { ЗНОЛП-10 У2 } \\
10000 / 100 \\
\text { (ZNOLP-10 U2 } \\
10000 / 10)\end{array}$ & -0.16670 & -0.04 \\
\hline $\begin{array}{l}\text { Voltage } \\
\text { transformer }\end{array}$ & $\begin{array}{l}\text { НАМИТ-10- } \\
\text { 2УХЛ2 } \\
\text { (NАМІТ-10- } \\
\text { 2UKhL2) }\end{array}$ & -0.05880 & -0.04 \\
\hline
\end{tabular}

Let us consider some operation examples concerning the EE, which is presented in this report.

Example 1. Let us assume that some $\mathrm{EE}$ has been in operation during seven years under n.c. of operation. In this case its actually consumed service life length will also be equal to seven years. If that $\mathrm{EE}$ were running during seven years under heavier conditions, with $\mathrm{A}$ being equal to 1.1 , then in reality it would draw down a period of 7.7 years. If EE during that period of seven years were running under lighter conditions, with $\mathrm{A}$ being equal to 0.8 , then it would spend 5.6 years. If later on $\mathrm{EE}$ is going to be operated under n.c., then its remaining normative service life will be defined by Expression (13) and, accordingly:

$$
\begin{aligned}
& \mathrm{R}_{0 . \text { rem. }}=25-7=18 \text { years; } \\
& \mathrm{R}_{0 . \text { rem. }}=25-7.7=17.3 \text { years; } \\
& \mathrm{R}_{0 . \text { rem. }}=25-5.6=19.4 \text { years; }
\end{aligned}
$$

If after that it is scheduled to operate that $\mathrm{EE}$ under certain conditions which will differ from its normative ones, then the value $\mathrm{R}_{0 . \text { rem. }}$ will have to be corrected.

Example 2. Let us imagine that some EE during two years, following the start up of its operation, was running under normative conditions, and after that during the next three years it was running under lighter conditions, with A being equal to 0.9 , and then during the following five years it was running under heavier conditions, with Factor $\mathrm{A}=1.2$. In that case the actually consumed service life of that EE, bearing in mind the additivity property referred to earlier (ref. to Expressions (7)), will be determined as the sum of actually spent service life during any single interval of its accrued calendar-based operating time:

$$
\mathrm{R}_{\mathrm{K}}=2 \cdot 1+3 \cdot 0.9+5 \cdot 1.2=10.7 \text { years. }
$$

Therefore, during the ten years of $(2+3+5)$ of its accrued calendar-based operating time, that EE actually had used up 10.7 years of its service life. If later EE is going to be operated under normative conditions, then its remaining normative service life can be determined by the following expression (13):

$$
\begin{gathered}
\text { Normative conditions: } \\
\mathrm{R}_{0 . \text { oct }}=25-10.7=14.3 \text { years. }
\end{gathered}
$$

If further on it is scheduled to operate EE under those conditions which will differ from its normative ones, then the value $\mathrm{R}_{0 . \text { rem. }}$ has to be corrected by applying Expression (17). If, for instance, it is scheduled to run $\mathrm{EE}$ under lighter operating conditions (with $\mathrm{A}=0.8$ ), then:

$$
\mathrm{R}_{\text {ост }}=\int_{\mathrm{R}_{\mathrm{K} . \mathrm{i}}}^{\mathrm{R}_{0}} \frac{1-\mathrm{S}(\mathrm{r})}{1-\mathrm{S}_{0}(\mathrm{r})} \mathrm{dr}=\int_{10.7}^{25} \mathrm{Adr}=\int_{10.7}^{25} 0.8 \mathrm{dr}=11.44 \text { years. }
$$

In that case we shall have the following relationship: $\mathrm{R}<\mathrm{R}_{0 . \text { rem. }}(11.44<14.3)$, and, consequently, equipment operation can be prolonged by $14.3-11.44=2.86$ years. If after that period EE is going to be run under service conditions which will differ from its normative ones, then the value of 2.86 years will have to be corrected too, in order to find out how long more it will be capable of running. If its operation conditions are going to be heavier, then EE will be able to run less time, not during 2.86 years. If, for example, $\mathrm{A}=1.1$, then $\mathrm{EE}$ will have used up the period of 2.86 after 2.6 years of its accrued calendar-based operating time:

$$
2.86=\int_{10.7+11.44}^{\mathrm{r}_{\mathrm{KH}}+10.7+11.44} 1.1 \mathrm{dr}=1.1 \mathrm{r}_{\mathrm{KH}} \Rightarrow \mathrm{r}_{\mathrm{KH}}=\frac{2.86}{1.1}=2.6 \text { years. }
$$

Summing it up, EE will be able to run during $10.7+11.44+2.6=24.74$ years, before it completely exhausts its service life and can pass into a limit state.

The examples presented herein prove the possibility to calculate EE technical service life, taking into account the well-known function of EE SI variations, depending on the accrued calendar-based operating time of electrical equipment. 


\section{Conclusions}

An approach has been worked out to evaluate the values of EE spent service life, with account taken of the changing nature of its integrated characteristic, i.e, that of its status index. This approach combines also some previously developed methods of evaluating equipment service life and status index, and it allows to evaluate the numerical values of $E E$ used up service life as a dependence of its actual accrued operating time, taking into account its real operation conditions and modes, and this is supported by the examples given herein.

Therefore, during EE operation in practical applications it is necessary to correct EE normative service life, considering concrete operation conditions and modes, and in such a way to obtain actual data concerning both the EE accrued and remaining operating time. The said calculation of service life length on the basis of the trend of status index variations allows us to assess how EE had actually been running under concrete operation conditions and how long it will still be able to work under predicted conditions.

\section{References}

1. D.A. Andreyev, A.N. Nazarychev, A.I. Tadzhibaev. Determination of the Probability of Equipment Failures in Power Network Companies on the Basis of Technical Status Evaluation (FSAEE «PPEIPD». - St.Pb., 2017. - 194 p).

2. R.N. Berdnikov, D.B. Gvozdev, I.A. Kuzmin, A.N. Nazarychev, D.A. Andreyev, A.I. Tadzhibaev. Collected Science-Technical Reports by a Team of Employees of the "ROSSETI" Group of Companies». (M.: "Electric Energy. Transmission and Distribution", p.p. $151-163$. 2017).

3. A.N. Nazarychev, E.V. Novomlinskiy, D.A. Andreyev. The Methodological Aspects of Investigations Concerning Large Energy Sector Systems. Issue 67. "The Problems of Reliability of Energy Sector Systems". (Syktyvkar: The Komi Republican Printing Press Publishing House", 2016. - p.p. 171 - 179). 